with a discussion of the conversion of camphene hydrochloride to isobornyl chloride and develops into an examination of the evidence for non-classical carbonium ions. Later topics discussed include the evidence for internal return and homo-allylic interaction. The mechanistic information available on these bicyclic rearrangements necessarily produces a rather complex pattern, but the author is to be congratulated on the presentation and development of his arguments so that the chapter is always clear and readable. The migrations to electrondeficient nitrogen or oxygen appear to provide a slightly simpler field, but one in which a number of problems are still unsolved. These topics are clearly discussed by P. A. S. Smith; the account of the Beckmann rearrangement being particularly complete.

The majority of the other chapters reach the same high standard. The first, rather short, chapter by Pocker provides interesting reading because of his critical assessment of the evidence for various types of intermediates and transition states. The chapter on "Aromatic Rearrangements" by Dewar ably defends the thesis that $\pi$-complexes are involved in the main intramolecular aromatic rearrangements, but I had the feeling that some awkward facts were being too easily dismissed, as, for example, the deuterium solvent effect on the rate of the benzidine rearrangement (p. 341). The other chapters include a valuable discussion of the thermal, acid-catalysed and base-catalysed rearrangements of cyclopropane and cyclobutane by Breslow.

It would be difficult for any single author to attempt a work of this kind, but the collaboration has made the volume appear as a collection of almost independent reviews. Each chapter is complete in itself, but the relationship and order of the individual chapters do not correspond to any obvious pattern based on the mechanisms involved. The delay in publication appears somewhat greater than necessary, for the chapter on "Aromatic Rearrangements" has only one reference later than 1959, and in other chapters references to work in 1960 have often been added as footnotes. However, some authors have used such footnotes to include a discussion of work published as late as 1962 .

The book is well produced, and the misprints appear to be few, although one of these has unfortunately added an extra hydrogen atom to the tricyclobutonium ion (p. 263), thereby modifying the symmetry of the system. The absence of a subject index and author index in this volume is regrettable, because some purchasers may not want both volumes.

Despite these minor criticisms, there is no doubt that Molecular Rearrangements succeods in its aim of showing how the apparent turmoil of organic rearrangements has slowly been reduced to the orderly consequences of a few simple concepts. In emphasizing the present uncertainties and diffieulties, some of the chapters also point the way to future progress.

J. H. RIDD

\section{MODERN BIOCHEMISTRY}

\section{Introduction to Modern Biochemistry}

By P. Karlson. Translated by Charles H. Doering. Pp. xviii +433 . (New York: Academic Press, Inc.; London: Academic Press, Inc. (London), Ltd., 1963.) $80 s$.

THE original German edition of this book was published a few years ago under the title Kurzes Lehrbuch der Biochemie für Mediziner und Naturwissenschaftler. The 1962 edition has now been translated by C. H. Dooring, of the University of California, and has been given the title Introduction to Modern Biochemistry. This is a more suitable title, for the author's approach to biochemistry is from the chemical rather than medical angle, and medical students will not find much about the biochemistry of disease. In order to cover the main fields of modern biochemistry in a book of this size, Prof. Karlson has found it necessary to omit most of the explanation of how the various reaction pathways were discovered. From the point of viow of teaching, this tends to restrict the usefulness of the book. For example, a student relying on this book would learn nothing about Knoop's classical experiments on fatty-acid oxidation, nothing about Wieland's work on biological dehydrogenation, and noth. ing about the exciting series of biochemical adventures which culminated in the formulation and verification of the citric acid cycle. Yet, the most interesting and worthwhile approach to these different aspects of biological oxidation is the historical one.

For advanced students who have time to read more widely, this book has much to recommend it. In particular, the chemical structures and reaction sequences are very clearly set out and are well explained in the text. There are helpful diagrams to illustrate aspects of stereochemistry and enzyme action, and some impressive electron micrographs. More space might well have been given to enzyme kineties, and the treatment of the important subject of enzym inhibitors is very inadequate. The book ends with a chronological table of important biochemical discoveries, starting with the discovery of urea which is attributed to Rouelle (1773). This table fails to include such revolutionary discoveries as the use of isotopes as tracers in biochemistry, or the development of chromatography in its different forms; moreover, it omits some of the greatest names in the evolution of biochemistry -Bernard, Willstätter. Hopkins, Cori, Szent-Györgyi, for example. Perhaps in future editions this table might bo expanded to give a more balanced picture of how biochemistry developed. Each chapter onds with a short bibliography, mostly of books in English, and there is a folding chart, summarizing the chief metabolic pathways and their interrelationships, and showing, on the other side, the sequence of amino-acids in the protein chains of adult human hæmoglobin. In spite of certain defects which are mainly attributable to its restricted size, this volume is a useful addition to the list of modern text-books of biochemistry.

D. C. HaRrison

\section{NUTRITION AND DIETETICS}

\section{World Review of Nutrition and Dietetics}

Vol. 4. Edited by Geoffrey H. Boume. Pp. vi +162. (London: Pitman Medical Publishing Co., Ltd., 1963.) $60 s$.

$\mathrm{N}$ this fourth volume of the World Review of Nutrition 1 and Dietetics, the international distribution of the reviews is well upheld with the eight contributions from France, Yugoslavia, Switzerland, the United States, Israel, Belgium, Scotland and England. The reviews are somewhat uneven in value, and a tougher editorial hand would have enhanced their readability. This applies particularly to papers where the original draft was presumably not in English and inept wording tends to obscure the meaning.

The useful discussion of the validity of present-day ideas of public health nutrition from Dr. Tremolieres (National Instituto of Hygiene, Paris) unfortunately loses some of its drive in translation. The author has much to contribute from his own experience of work in nutrition of developing communities. His criticisms of interpretations of survey data and of recommendations of expert committees are well founded.

It is interesting to have reports on the nutritional situation in Yugoslavia from Dr. Ferber (Central Institute of Hygiene, Zagreb) and of the situation among the peoples of remote mountain villages in Switzerland from Dr. Verzàr and Dr. Gsell (Basle). In both these countries, 